\title{
US decides close tabs must be kept on xenotransplants...
}

\section{Declan Butler}

It may not be much of a silver lining. But recent US experience with clinical trials of gene therapy appears to have helped persuade the government that trials of transplants from animals to humans xenotransplants - should be subject to strict federal regulation.

The move, outlined under government guidelines published on 25 May, acknowledges the risk that xenotransplants might introduce virulent viruses into humans. It represents a significant tightening of previous guidelines issued by the Public Health Service (PHS) four years ago.

The PHS produced the new draft after discussion among its component agencies: the Centers for Disease Control and Prevention, the Food and Drug Administration (FDA), the Health Resources and Services Administration, and the National Institutes of Health (NIH). The draft states that "all xenotransplant products pose a risk of infection and disease to humans" and that "all species pose infectious disease risks".

Earlier guidelines would have left approval of clinical trials to local university review boards. The new draft recommends instead that all clinical trials are approved by the FDA, and that xenotransplantation be overseen by a new committee, the Secretary's Advisory Committee on Xenotransplantation (SACX; see opposite).

"It is another strong step in making sure that any clinical trials are done in a fashion that is consistent with national policies rather than local views, which may be subject to influence or lack of critical expertise," says Dan Salomon, a researcher at the Scripps Research Institute, former head of the American Society of Transplant Surgeons, and a leading xenotransplant proponent.

The recent controversy over the reporting of side effects in gene-therapy trials has helped the FDA withstand the current antiregulatory climate in the United States, says Jonathan Allan, a virologist at the Southwest Foundation for Biomedical Research in San Antonio, Texas, and a member of the FDA's advisory subcommittee on xenotransplantation. The FDA "now feels it can regulate the field of xenotransplantation", he says.

The earlier draft would have allowed transplants from non-human primates, despite the virological risk. The new document reaffirms an earlier FDA moratorium on such trials.

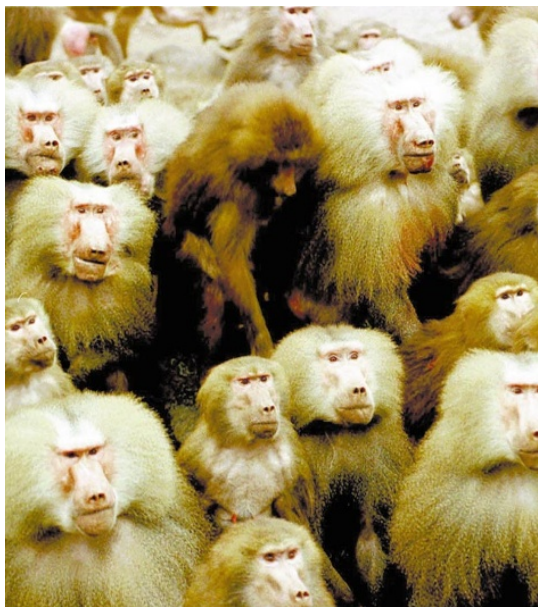

No monkey business: a ban on transplants from non-human primates has been retained.

Allan, who has long campaigned against transplants from non-human primates, agrees that the guidelines "are a significant improvement”. But he is concerned that the PHS position remains ambiguous, suggesting that the SACX "make recommendations on the questions of whether and under what conditions the use of non-human primate xenografts would be appropriate".

There is provision for imported animals to be used when the "species or strain are not available for use in the United States and their use is scientifically 
warranted". Designed to allow companies such as Novartis to import transgenic pigs, this loophole could lead to use of virus-laden wild animals, says Allan.

The document does not go into detail on the viruses that need to be considered in risk assessment, or species-specific differences, leaving this for the FDA to consider for each protocol. Difficulty in assessing the risk is the major caveat to proceeding. Although the guidelines emphasize the need to assay tissues for viruses, in reality most new viruses are only detected after the event.

Most research on pig viruses has focused on those that cause losses to pig farmers. Little is known about viruses, such as herpes and retroviruses, that cause low-lying infections that might be dangerous to humans.

"I still worry about the infectious disease risks," says Allan. "But if there are promising therapies, such as pig neuronal cells to treat Parkinson's disease, that could benefit millions it changes your notion of how to go forward." Such cells may be less dangerous than whole-organ transplants. But more work is needed to develop primate models for viral infection.

Abdullah Daar, a surgeon and bioethicist at Sultan Qaboos University in Oman, says the new guidelines are "much tougher", but is sceptical as to how they will be implemented. They require sponsors of trials to ensure informed consent of patients, their families and close contacts, for example, and long- term surveillance of subjects. But several observers doubt that this is feasible.

The PHS also recommends that blood and tissues samples and all records of trials be kept for 50 years. Salomon wonders who will pay for such a proposed national database: "Industry will be reluctant, and there is certainly no evidence that the FDA could budget such a project."

"The PHS is determined to go ahead with clinical trials, but if we are putting the public at risk then broad public consultation is needed, and not decisions by experts," says Fritz Bach, a xenotransplant researcher at Harvard Medical School, Boston, who has called for a moratorium on trials.

But André La Prairie, an official at Health Canada, the country's equivalent of the FDA, says that "the guidelines are a clear message that limited controlled trials in xenotransplantation will continue”.

\section{... and sets up a body to oversee trials}

Paul Smaglik, Washington

The US Department of Health and Human Services is to augment the panoply of government regulatory bodies by setting up a Secretary's Advisory Committee on Xenotransplantation (SACX) to oversee the technology.

The new committee will review proposed clinical trials and monitor ongoing trials, much as the Recombinant DNA Advisory Committee (RAC) of the National Institutes of Health (NIH) endorses novel gene-therapy protocols and monitors 'adverse events' in trials already under way.
But the role of the SACX in deciding which trials go ahead remains unclear. "There's been no decision yet on how it will work in terms of reviewing protocols," says Mary Groesch, a policy officer at the NIH's Office of Biotechnology Activities who is handling nominations for the SACX.

The Food and Drug Administration (FDA) will have the final say in approving clinical trials. In gene therapy, it is the NIH director, and ultimately the FDA, which has the last word.

In the early 1980s, the RAC approved the first human clinical gene-therapy trial. By the 1990s, its responsibility was restricted to approving new types of protocol (see Nature 384, 297;1996).

More recently, some critics have called for the RAC to stop examining new protocols altogether to focus on education, as the oversight of gene therapy by both the FDA and NIH has led to confusion, especially over reporting adverse events.

Researchers hope that, by sticking to a narrow mission, the SACX will attract less critical flak than the RAC. 